\title{
System Dynamics Model for Systematic Evaluation of China's Financial Risk
}

\author{
Jinghong Xu $\mathbb{D},{ }^{1,2}$ Daguang Yang $\mathbb{D},{ }^{1}$ and Qian Zhang $\mathbb{D}^{3}$ \\ ${ }^{1}$ Business School, Northeast Normal University, Changchun 130117, China \\ ${ }^{2}$ Business School, Changchun Humanities and Sciences College, Changchun 130117, China \\ ${ }^{3}$ International Business School, Jilin International Studies University, Changchun 130117, China \\ Correspondence should be addressed to Qian Zhang; zhangqian@jisu.edu.cn
}

Received 5 December 2021; Revised 18 January 2022; Accepted 19 January 2022; Published 14 February 2022

Academic Editor: Tongguang Ni

Copyright ( $\odot 2022$ Jinghong Xu et al. This is an open access article distributed under the Creative Commons Attribution License, which permits unrestricted use, distribution, and reproduction in any medium, provided the original work is properly cited.

Finance is becoming more important in the national economy. Maintaining financial stability is critical not only for the financial industry's prosperity and development, but also for a country's political, economic, and social development. This paper will look at the mechanisms that cause systemic risk to develop and evolve, as well as how to measure systemic financial risk in multiple dimensions. To begin, create a system for evaluating financial risk in a systematic manner. Second, using the AHP and CRITIC methods to determine various indicators and market weights, create a systemic financial risk evaluation model based on the system dynamics model, and calculate the system from 2010 to 2019 comprehensive financial risk index. Finally, simulation research is conducted using the system dynamics model of systemic financial risk, and the simulation results are analyzed. The findings show that China's financial risk has been gradually increasing since 2016, with relatively small fluctuations in risk state.

\section{Introduction}

Systemic financial risks not only occur in financial markets, but also affect macroeconomic and social wealth, according to international social practice [1]. Financial globalization will, without a doubt, benefit China's financial industry. It has the potential to introduce more efficient and diverse funds, introduce international advanced management concepts and innovative thinking, and revitalize China's financial system. However, there are no benefits on either end, and financial globalization has numerous drawbacks $[2,3]$. It may increase a country's economy's risk exposure and the financial system's vulnerability to external pressure, raising the possibility of systemic financial risks. Overall, the financial system's operation has a twofold impact on economic development [4]. It has the potential to boost economic growth while also increasing the likelihood and severity of systemic financial risks escalating into financial crises. As a result, systemic financial risk research is particularly important at this stage.
Studies have not designed scenarios for systematic financial risk early warning, but there are differences in systematic financial risk monitoring and early warning under different scenarios $[5,6]$. In these studies, empirical research is the majority, while theoretical research is the minority. In empirical research, empirical research on fundamentals and trade channels is the majority, while relatively few focus on financial channels and expectations $[7,8]$. Scholars in China have gradually focused their attention on financial contagion research, but due to a lack of data sources and theoretical mechanisms, the existing research results are mostly broad theoretical introductions, with little in the way of specific path analysis and empirical testing of financial risk contagion mechanisms [9-11]. The system dynamics model is used in this paper to investigate the systematic financial risk early warning mechanism of internal driving mechanism. The interaction of these influencing factors (the product interaction term in the econometric model) is used to identify the systematic financial risk on this basis. 
A typical system model for the processing and analysis of highly nonlinear [12] and large-scale complex problems is [14] the system dynamics model [13]. We can simulate the real system and find the target problem's solution strategy by establishing a dynamic simulation model. The vast and multilevel structure of the financial ecosystem influences the structural change of systemic financial risk. Each level of risk in the systemic financial risk contains a large number of elements, which in turn make up the elements of the previous level of risk. Each level's elements are autonomous individuals who will have a diverse impact on the systemic financial risk associated with the activities. As a result, the systematic financial risk evaluation model in this paper is built using Vensim software and is based on the idea of a system dynamics model.

\section{Related Work}

Because systemic financial risk has such a large impact on a country's financial security and even global financial stability, it has piqued academic interest. Systemic financial risk, for example, is defined as the risk that the entire financial system will collapse or cease to function. This intuitive definition, on the other hand, is very unfavorable for measuring and analyzing systemic risk, particularly for the development of macroprudential supervision, which has drew scholars' attention. A comprehensive study on the measurement and early warning of systemic risk has been published in [15], but few scholars have looked at the overall study of systemic risk in China [16]. It was confirmed that there is a systemic risk spillover effect in listed commercial banks in China, especially during the crisis, by measuring the fluctuation of stock prices of 12 listed banks in China and constructing a quantile regression model. Literature $[17,18]$ further points out that there is a direct positive correlation between the size of banks and their risk contribution and negative externalities, and the magnitude and direction of risk spillover effects have an important influence on the stability of the financial system. Literature [19] holds that systemic financial risks will seriously damage the operational ability of the financial system, and it is difficult for the financial system to maintain stability. Its fragile characteristics will affect economic growth and social welfare and even threaten the whole financial system and macroeconomic stability. Literature [20] holds that systemic financial risk will lead to a wide range of financial service failures, resulting in partial or total losses of the financial system, and then the risk of serious impact on the real economy.

The structured method, which uses data from financial statements such as balance sheets of financial institutions to calculate the joint impact distribution of crises and then measures financial risks on that basis, is the most widely used of the major international financial risk measurement methods. Literature [21] uses quantile regression technology to calculate the systemic risk of the entire financial sector under the assumption of a single bank asset loss. According to [22], the financial stress index can measure the degree of potential risks faced by financial markets, making it the explained variable of the degree of systemic financial risks, while other leading indicators of financial risks are explained variables of systemic financial risks. Literature [23] assumes that systemic financial risk is a one-time occurrence. If $Y$ is used to represent the crisis variable, it can only take the values 0 or 1 , indicating that the crisis has not occurred or has occurred, respectively, and $X$ is the above-mentioned crisis influencing factor. Literature [24] investigates past crisis events, identifies leading indicators of the crisis, and establishes a threshold for each indicator, which is determined using the "noise-signal ratio" method. The research method based on tail risk probability was used in [25]. It used the extreme value measurement method to estimate the tail risk of China's financial market and used it as the basis for measuring systemic risk. Literature [26] uses the RMB foreign exchange market pressure index to study the release process and effect of pressure, while [27] uses the vector autoregressive model of regional Markov matrix transfer to study the systemic risk of China's financial market and provides an early warning for future risks.

\section{Research Method}

\subsection{Analysis of Influencing Factors of Systemic Financial Risk}

3.1.1. Macroeconomic Operation Risk. A good macroeconomic environment is required for the effective operation of the financial markets. The financial market's effectiveness will be hampered as the macroeconomic operating environment deteriorates, resulting in unsustainable financial market stability and the emergence of systemic financial risks. The quality of a country's macroeconomic environment is influenced by the overall economic operation. The overall economic operation risk refers to the possibility that the economic operation deviates significantly from the equilibrium state. In practice, the degree of realization of macroeconomic development goals is often used to measure the overall economic operation risk. Therefore, the adjustment of industrial structure leads to the slowdown of economic growth, the difficulties of non-state-owned enterprises lead to the deterioration of employment environment, the internationalization of $\mathrm{RMB}$ aggravates the imbalance of international payments, and the inflation caused by high leverage will all have negative effects on the stability of financial order.

3.1.2. Financial Market Risk. On the one hand, financial market development can quickly and effectively guide the rational flow of funds and improve the efficiency of capital allocation; on the other hand, it has a pricing function, and financial market price fluctuation promotes financial innovation, increasing market volatility and bringing financial market risks while realizing risk dispersion and transfer. The stock market, credit bond market, and foreign exchange market are currently the most influential markets in China's financial market, and their risk characteristics are the most obvious. Although there has been no large-scale bond default in China's credit bond market in recent years, as the size of corporate credit bonds grows, the future debt repayment burden and pressure will grow, and the credit bond 
market's potential risks will intensify, posing systemic financial risks. The internationalization of the RMB, the opening of capital accounts, and the establishment of an offshore RMB market have brought the Chinese financial market and the international financial market closer together, and the risks of the international financial market have spread to the domestic financial market via a variety of channels. Therefore, financial market risk includes three dimensions: stock market risk, credit bond market risk, and foreign exchange market risk.

3.1.3. Financial Institution Risk. Financial institutions are an important part of the main body of financial ecology. Although financial innovation has given birth to diversified new financial institutions, at present, banks, securities, and insurance are still the most important financial institutions in China, and their risk levels and risk contagion among them play a vital role in the fluctuation of systemic financial risks. The risk contagion among financial institutions has contributed to the outbreak and spread of systemic financial risks. Therefore, financial institution risk is a collection of bank risk, securities risk, and insurance risk.

3.1.4. Risks of Nonfinancial Enterprises and Residents. The study of systemic financial risks should not be limited to financial institutions, financial market risks, or risk agglomeration and diffusion in the financial industry. To expand the research radius of systemic financial risks, we should pay close attention to all types of risk factors exposed in the development of nonfinancial enterprises and residents' consumption, as well as the transmission of risk factors to the financial industry.

3.2. Construction of Systematic Financial Risk Evaluation Index System. According to the definition and connotation of systemic financial risk, financial risk exists in different financial institutions or systems, so it is impossible to evaluate it by a simple method based on a single index data, but many factors must be considered. This paper selects the measurement index of systemic financial risk from four aspects: macroeconomic operation risk, financial market risk, financial institution risk, and financial enterprise and resident risk. The evaluation index is shown in Figure 1.

\subsection{Construction of Systematic Financial Risk Evaluation} Model Based on System Dynamics Model. The system dynamics model has obvious benefits when dealing with complex social system problems, particularly those that are nonlinear, are dynamic, and require low accuracy. The essence of the system dynamics model, from the standpoint of research thinking, is the concrete application of each theory in the research target field; from the standpoint of research, the system dynamics model is to bring various factors that affect the research objectives into the research framework and form a model for experiments.
3.3.1. Causality Diagram and Model Structure of Each Subsystem. To assess the systematic financial risk, we must first grasp its structure. Assume that the structural framework serves as the foundation for data classification and organization.

In this paper, the analysis of systemic financial risk is based on four primary risk indicators: macroeconomic operation risk, financial market risk, financial institution risk, and nonfinancial enterprise and resident risk. Therefore, this part is divided into four subsystems: macroeconomic risk subsystem, financial market risk subsystem, financial institution risk subsystem, and nonfinancial enterprise and resident risk subsystem to analyze the correlation among each subsystem (Figure 2).

3.3.2. Determination of All Levels of Weights of Systematic Financial Risk Evaluation Model from the Financial Perspective. Determining the reasonable index weight is very important to build a complete and scientific systematic financial risk evaluation model. At present, there are three main methods to determine the index weight:

(1) Subjective empowerment methods that are "function-driven" are highly dependent on experts' knowledge and experience, but the evaluation results can reflect the subjective preference of decision makers.

(2) The objective weighting method that is "differencedriven" determines weights by rigorous mathematical logic reasoning. Its main advantage is that it does not reflect the subjective color of decision makers but is based on the information characteristics of decision matrix.

(3) Integrated weighting method is present.

When comparing the first and second types of weighting methods, we can see that the objective weighting method relies on the system's mathematical and optimization theory, and it is extremely objective to deduce the weighting through rigorous mathematical deduction, but the weights obtained by this method are frequently contrary to the actual situation and difficult to explain, and this method is highly dependent on the selected model and data, and the weights obtained by different models are often quite different, lacking inheritance and order preservation. Although the outcome of the subjective weighting method is subjective and arbitrary, it is excellent in terms of explanation, inheritance, and maintaining order.

Therefore, this article also adopts the subjective and objective weighting method to ensure the reliability and authenticity of the weights: subjective weighting adopts the AHP (Analytic Hierarchy Process) method, and objective weighting chooses the CRITIC (Criteria Importance through Intercriteria Correlation) method.

Using AHP method, first of all, the relative importance of each factor to the target at the next higher level is assigned with 9-level Bipolar scale. For any target in the decisionmaking system, a judgment matrix is formed by pairwise 


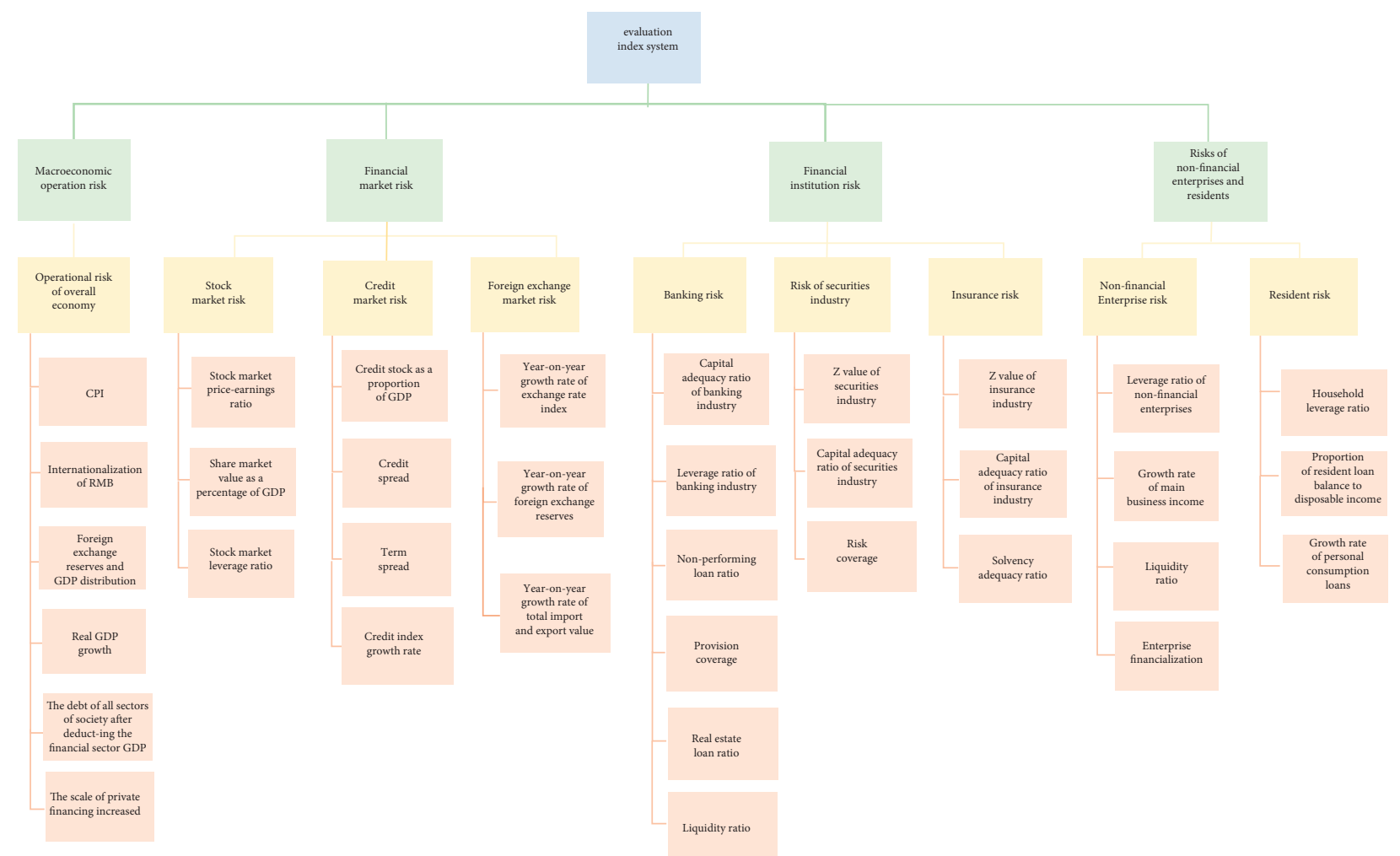

FIgURE 1: Systematic financial risk evaluation index system.

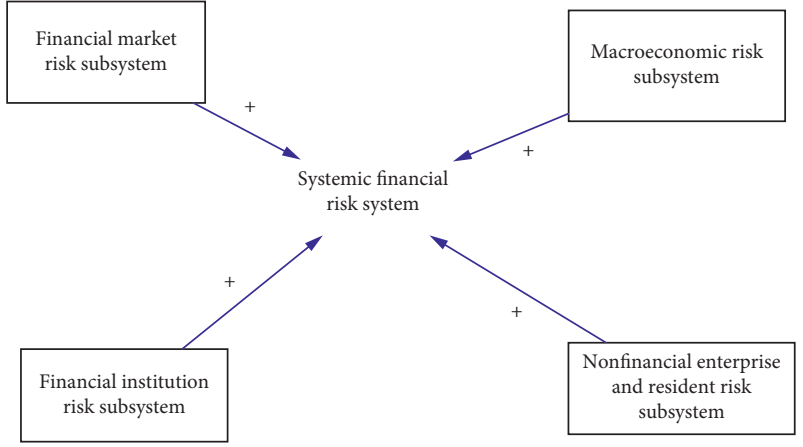

Figure 2: Structural diagram of systematic financial risk model. judgment between the next level indicators. Take any firstlevel indicator $A_{i}$ as an example, the corresponding number of second-level indicators is $m$, and $b_{c d}$ is the importance ratio of the second-level indicators $A_{i c}$ and $A_{i d}$ to $A_{i}$, then the judgment matrix expression is as follows, the importance meaning of $b_{c d}$ value is as shown in Table 1 , and $b_{c c}=b_{d d}=1$.

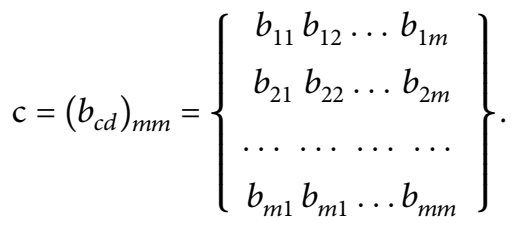

Secondly, the relative weight is calculated by the judgment matrix.

Step 1. calculate that product of elements in each row of the judgment matrix:

$$
\mathrm{M}_{c}=\prod_{d=1}^{m} b_{c d} \quad c=1,2, \ldots, m .
$$

Step 2. calculate the $m$-th root of $M_{c}$ :

$$
\omega_{i c}=\sqrt[m]{\mathrm{M}_{c}} \quad c=1,2, \ldots, m .
$$

Step 3. carry out vector normalization on $\omega_{\text {ic }}$ :

$$
\mathrm{W}_{i c}=\frac{\omega_{i c}}{\sum_{c=1}^{m} \omega_{i c}} \quad c=1,2, \ldots, m .
$$

According to this method, $\mathrm{W}_{i 1}, \mathrm{~W}_{i 2}, \mathrm{~W}_{i c}, \ldots \ldots \mathrm{W}_{i m}$ are the weight of each secondary index to its primary index $A_{i}$, and the subjective weight coefficient of each index is obtained by analogy.

In order to ensure the rationality and correctness of the obtained feature vector, consistency test should be carried 
TABle 1: Grade 9 Bipolar scale assignment table.

\begin{tabular}{lc}
\hline Scale & Meaning \\
\hline 1 & Compared with indicator $d$, indicator $c$ is slightly more important. \\
3 & Compared with indicator $d$, indicator $c$ is more important. \\
7 & Compared with indicator $d$, indicator $c$ is particularly important. \\
9 & Compared with indicator $d$, indicator $c$ is extremely important. \\
$2,4,6,8$ & The intermediate value of the above adjacent judgment. \\
Reciprocal of the above scale & The importance ratio of $c$ to $d$ is $b_{c d}$, and then the importance ratio of $d$ to $c$ is $1 / b_{c d}$.
\end{tabular}

out. When the test is passed, the feature vector can be used as the weight vector; otherwise, the judgment matrix should be reestablished or corrected.

Consistency test formula:

$$
C R=\frac{C I}{R I}
$$

When $C R<0.1$, it is considered that the consistency test of the judgment matrix has passed.

Among them,

$$
C I=\frac{\left(\lambda_{\max }-n\right)}{(n-1)} .
$$

$\lambda_{\max }$ is the largest characteristic root; $R I$ is a random consistency index, and the values are shown in Table 2.

Diakoulaki (1995) proposed the CRITIC method, which uses contrast strength and conflict between evaluation indexes to determine the objective weight of evaluation indexes. Standard deviation is used to measure the intensity of the contrast between indicators, while the correlation coefficient is used to describe the conflict. CRITIC-based weighting indicators frequently have two distinguishing features: first, data fluctuation has a significant impact on the weighting; and second, data are frequently related. To assign objective weights to indexes, this paper employs the CRITIC method.

$G$ is defined as the amount of information in the systematic financial risk evaluation system. Then, for any firstlevel index $A_{i}$, the information content of the corresponding $c$-th second-level index $A_{i c}$ is

$$
g_{i c}=\sigma_{i c} \sum_{d=1}^{m}\left(1-r_{c d}\right), \quad c=1,2,3 \ldots \ldots m,
$$

where $\sigma_{i c}$ is the standard deviation of $\mathrm{A}_{\mathrm{ic}}$ and $\mathrm{r}_{\mathrm{cd}}$ is the correlation coefficient between $A_{i c}, A_{i d}$, so $\sum_{d=1}^{m}\left(1-r_{c d}\right)$ can represent the conflict between indicators.

The larger the $g_{i c}$, the more information it contains, and the higher the corresponding weight. Therefore, the objective weight $\varphi_{i c}$ of $g_{i c}$ is calculated as follows:

$$
\varphi_{i c}=\frac{g_{i c}}{\sum_{c=1}^{m} g_{i c}} \quad c=1,2,3 \ldots \ldots m .
$$

According to this method, the objective weight coefficients of indicators at all levels are obtained.

The measurement of systemic financial risk index is, in the final analysis, the measurement of risk index in four aspects: financial market, financial institutions, nonfinancial enterprises and residents, and overall economy. At the same time, the overall level of systemic financial risk can be obtained by synthesizing according to their respective weight proportions.

\section{Results Analysis and Discussion}

4.1. Determination of Data Source and Initial Value of Model. Part of the original data and information in this model comes from reputable public databases like the China Statistical Yearbook and wind, while the rest comes from official websites like the IMF and the People's Bank of China. Because the most recent China Statistical Yearbook is the 2020 Yearbook, with data up to 2019, the evaluation period for systemic financial risk in this paper is 10 years, from 2010 to 2019.

As the table function value, take the growth of each three-level index from 2010 to 2019 . Before using the model for evaluation, dimensionless treatment of the data of threelevel indicators should be performed in order to make the data more comparable. According to formula (8), indicators with a positive correlation with secondary targets are positively dimensionless, whereas indicators with a negative correlation with secondary targets are inversely dimensionless (9).

$$
\begin{aligned}
& x^{\prime}=\frac{x-\min (x)}{\max (x)-\min (x)}, \\
& x^{\prime}=\frac{\max (x)-x}{\max (x)-\min (x)} .
\end{aligned}
$$

Take the weight of each index as the ratio constant of the model. The index weights of all levels in the model are weighted by AHP method with subjective weighting and CRITIC method with objective weighting, respectively.

\subsection{Model Test Result Analysis}

4.2.1. Consistency Test Result. Consistency test is carried out on the judgment matrix of indicators at all levels of systemic financial risk, and the test results are shown in Table 3.

From Table 3, it can be seen that the judgment matrices of decision-making objectives at all levels of systemic financial risk have passed the consistency test. AHP is effective in empowering. 
TABLe 2: Numerical value of random consistency index $R I$.

\begin{tabular}{lllcccccccc}
\hline Order & 1 & 2 & 3 & 4 & 5 & 6 & 7 & 8 & 9 & 10 \\
\hline R.I. & 0 & 0 & 0.58 & 0.9 & 1.12 & 1.24 & 1.32 & 1.41 & 1.45 & 1.49 \\
\hline
\end{tabular}

TABLE 3: Consistency test result.

\begin{tabular}{|c|c|c|c|c|c|c|}
\hline Index & $\begin{array}{l}\text { Judgment } \\
\text { matrix order }\end{array}$ & $\begin{array}{c}\text { Maximum } \\
\text { characteristic root } \\
\lambda_{\max }\end{array}$ & $\begin{array}{l}\text { Consistency } \\
\text { index } C I\end{array}$ & $\begin{array}{l}\text { Average random } \\
\text { consistency index } \\
R I\end{array}$ & $\begin{array}{l}\text { Consistency } \\
\text { index } C R\end{array}$ & $\begin{array}{l}\text { Have you passed the } \\
\text { consistency check? }\end{array}$ \\
\hline Financial market risk & 3 & 3.006 & 0.003 & 0.58 & 0.005 & Pass \\
\hline $\begin{array}{l}\text { Financial institution } \\
\text { risk }\end{array}$ & 3 & 3 & 0 & 0.58 & 0 & Pass \\
\hline $\begin{array}{l}\text { Nonfinancial } \\
\text { enterprises and } \\
\text { residents' risk }\end{array}$ & 2 & 2 & 0 & 0 & 0 & Pass \\
\hline Overall economic risk & 6 & 6.289 & 0.058 & 1.24 & 0.047 & Pass \\
\hline Stock market risk & 3 & 3 & 0 & 0.58 & 0 & Pass \\
\hline $\begin{array}{l}\text { Foreign exchange } \\
\text { market risk }\end{array}$ & 3 & 3.018 & 0.009 & 0.58 & 0.015 & Pass \\
\hline Credit market risk & 4 & 4.088 & 0.029 & 0.9 & 0.032 & Pass \\
\hline Banking risk & 6 & 6.11 & 0.022 & 1.24 & 0.018 & Pass \\
\hline Insurance risk & 3 & 3.009 & 0.005 & 0.58 & 0.009 & Pass \\
\hline $\begin{array}{l}\text { Risk of securities } \\
\text { industry }\end{array}$ & 3 & 3 & 0 & 0.58 & 0 & Pass \\
\hline $\begin{array}{l}\text { Nonfinancial } \\
\text { enterprise risk }\end{array}$ & 4 & 4.072 & 0.018 & 0.9 & 0.020 & Pass \\
\hline Resident risk & 3 & 3.014 & 0.007 & 0.58 & 0.012 & Pass \\
\hline
\end{tabular}

4.2.2. Model Operation Inspection. The Vensim software includes a model checking tool that checks the model for mechanical errors in equations, variables, and dimensional units. Nonstructural and logical surface errors, such as unit mismatch at both ends of the equation and negative stock variables, are referred to as mechanical errors. The system of financial risk equations from the perspective of financial ecology has passed the mechanical error test, and the model can run as a result of testing and adjustments.

4.2.3. Model Authenticity Test. Comparing historical data with model simulation data, if the error between them is less than $10 \%$, the model simulation value is considered to be valid, which is also called historical test. In this paper, four common indicators such as CPI, the growth rate of social financing scale, the share of stock market value in GDP, and the rate of nonperforming loans in the banking industry are selected as the test variables, and the test time is from 2010 to 2019 . The inspection results are shown in Figures 3-6. The error between the model simulation value and historical data is less than $4 \%$. The model has passed the authenticity test, and the model simulation is effective.

4.3. Analysis of the Evaluation Results of Systemic Financial Risk. We can construct an evaluation index describing China's systematic financial risk after determining the weight of the systematic financial risk evaluation index. We must not only grasp the state of financial risks as a whole, but also analyze the state of financial risks in each submarket in order to objectively and comprehensively assess China's systemic financial risks.
Systemic financial risks, structurally speaking, are ubiquitous and exist in various markets within the system, thus encompassing all aspects of systemic risks, in which submarkets are interconnected and form systemic financial risks. Overall, systemic financial risk is an evolving process, and the state of each stage will change as well, providing a description of the previous state as well as a hint of future development trends. As a result, an objective assessment of the state of systemic financial risk is required. Figures 7-12 depict the change trend of the systemic financial risk index.

First and foremost, based on the overall trend, other submarkets, in addition to financial institutions, are becoming increasingly risky. The pressure levels of macroeconomic operation risk, financial market risk, and nonfinancial enterprise and resident risk are all relatively close, and the risk trend is from low to high. The risks of nonfinancial enterprises and residents, as well as macroeconomic operation risks, are relatively stable in the early stages of the samples chosen in this paper, but they all show a one-way increasing trend in the later stages.

Second, from the standpoint of internal structure, each subrisk market's indexes are interconnected and collectively reflect systemic financial risks. We can see that financial institution risks are closely related to China's asset economy and that banks' credit business has always had a significant impact on China's stock market and has become a significant source of systemic financial risks, by analyzing the financial risk measurement results of financial institution risks. The risk of financial institutions has been fluctuating, and speculation is extremely dangerous. International hot money, influenced by the external market, has a constant impact on the domestic 


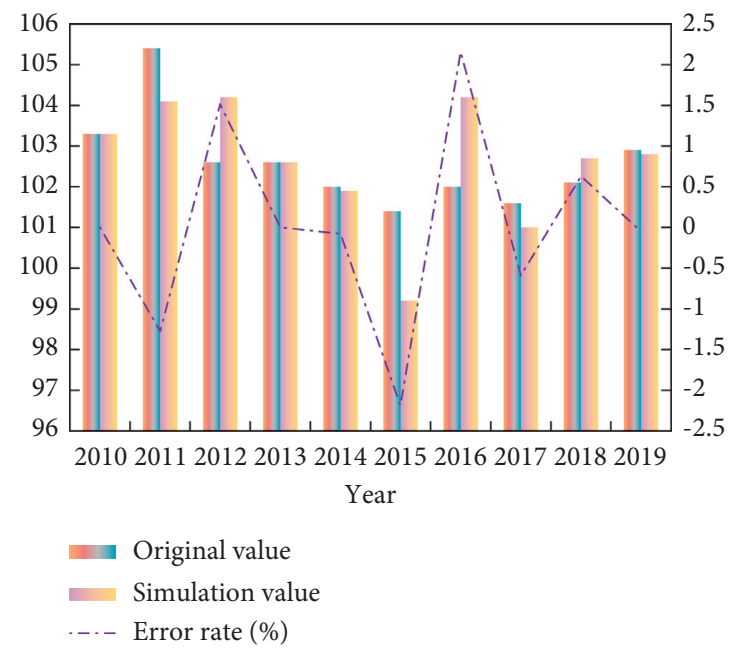

FIGURE 3: CPI authenticity test result.

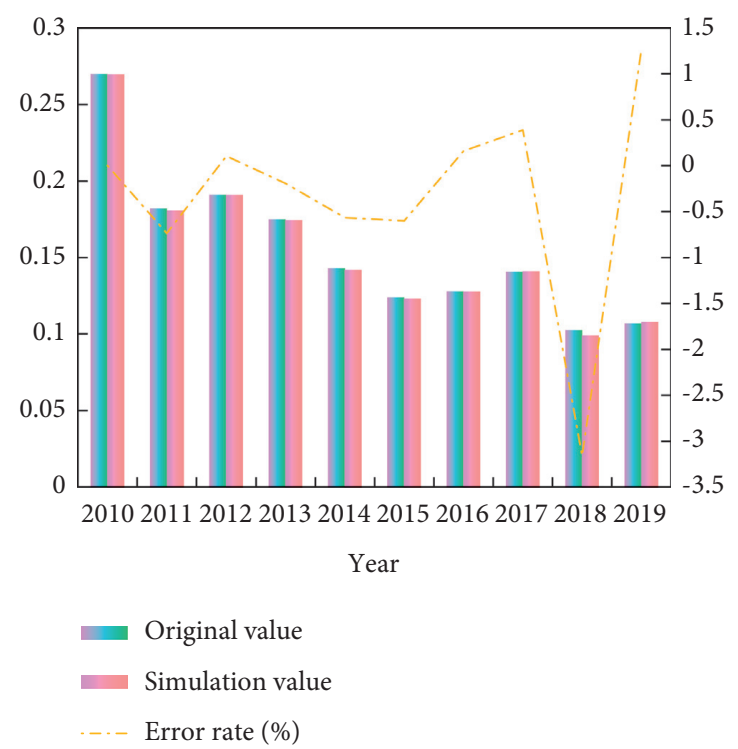

Figure 4: Truthfulness test results of social financing scale growth rate.

banking industry and stock market, and banks' rising financial risk drives the domestic stock market's rising financial pressure.

Then, from the perspective of fluctuation characteristics, there are significant differences in risk indices of each submarket. From 2010 to 2019, with the continuous promotion of interest rate marketization, the fierce competition among major banks increased the competition cost of small and medium-sized banks, and then the "money shortage" problem also highlighted the short-term liquidity problem faced by the banking system, which made the risk level of financial institutions improve in 2012. In terms of macroeconomic operational risk, the macroeconomic operational risk has increased to a certain extent. From these figures, it can be observed that the risk of nonfinancial enterprises and residents in China has been rising almost all the time from 2010 to 2019. On the whole, the financial risk fluctuation of financial institutions in China is not great. 


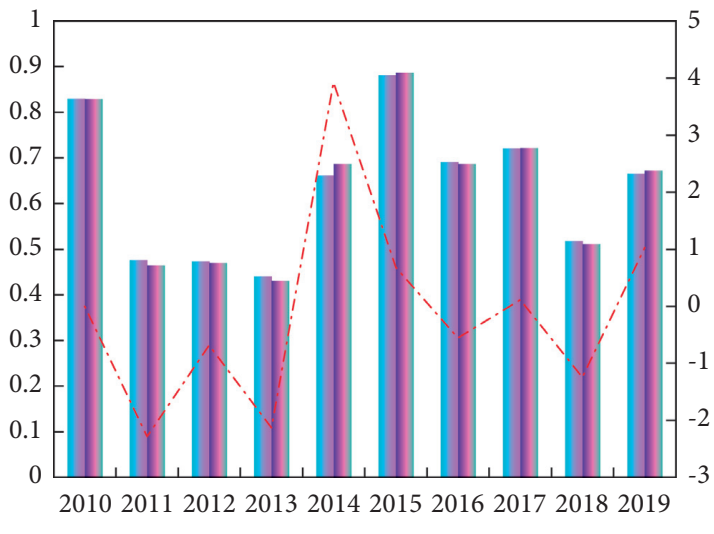

Year

$$
\begin{aligned}
& \text { Original value } \\
& \text { Simulation value } \\
& \text {..- Error rate (\%) }
\end{aligned}
$$

FIGURE 5: Authenticity test results of stock market value as a proportion of GDP.

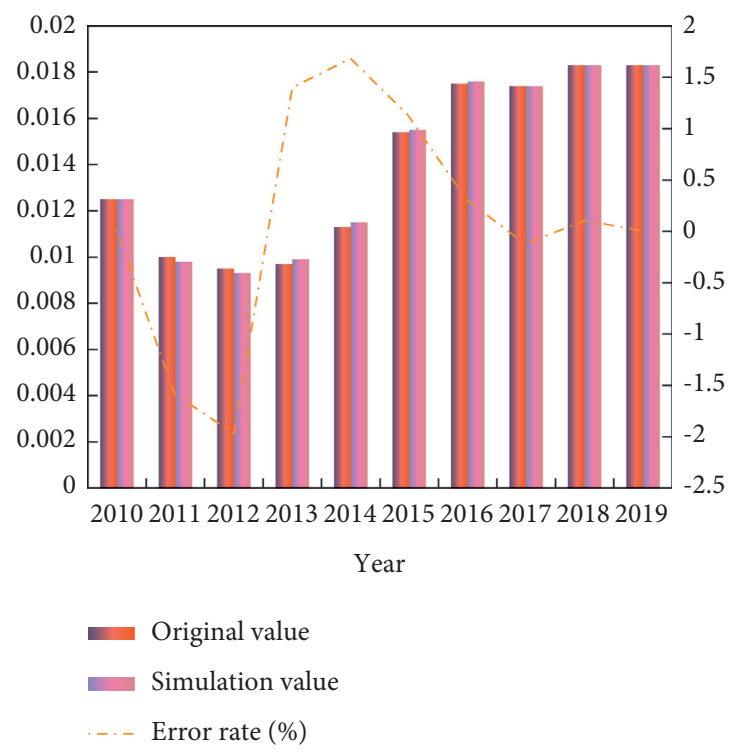

Figure 6: Truthfulness test results of nonperforming loan ratio in banking industry.

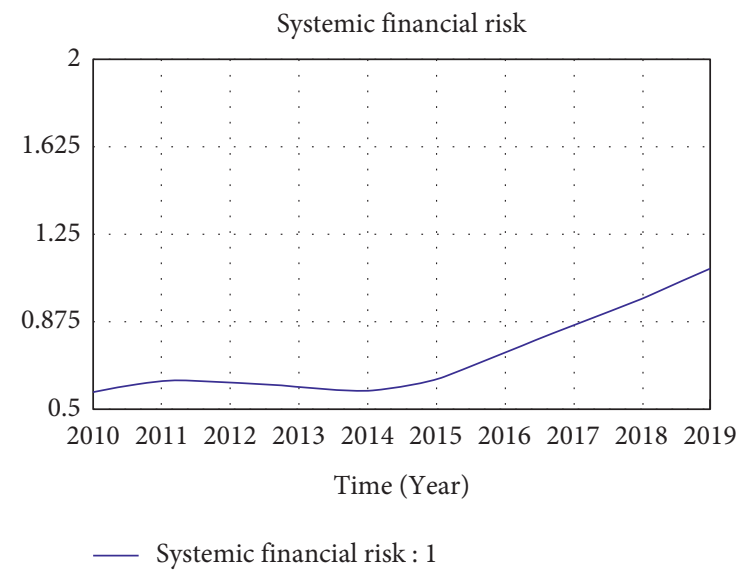

Figure 7: China's systemic financial risk level based on system dynamics model. 
1

Systemic financial risk

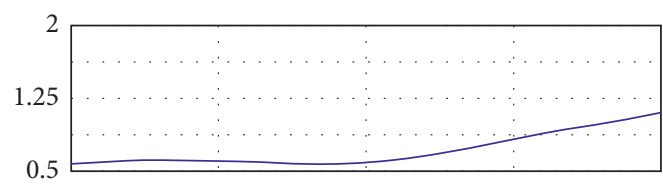

Macroeconomic operation risk

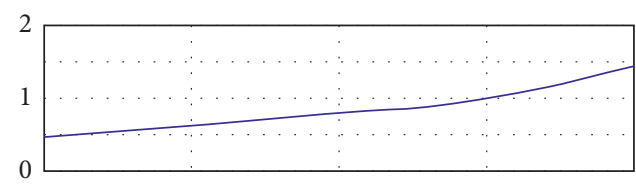

Financial market risk

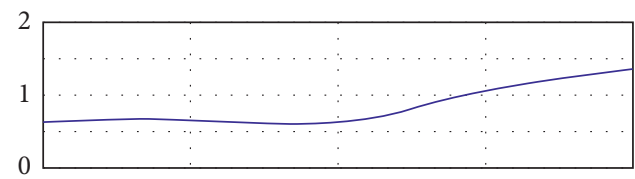

Financial institution risk

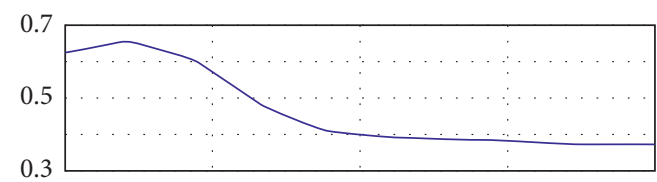

"Risks of non-financial enterprises and residents"

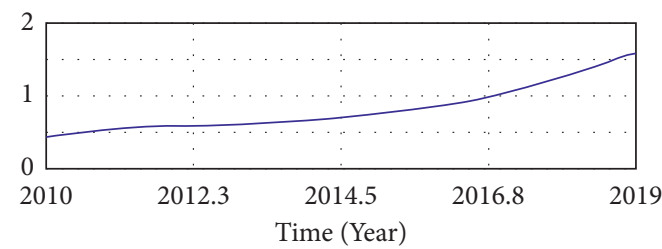

FIgURE 8: Comparison of systemic financial risk level and risk level of each subsystem.

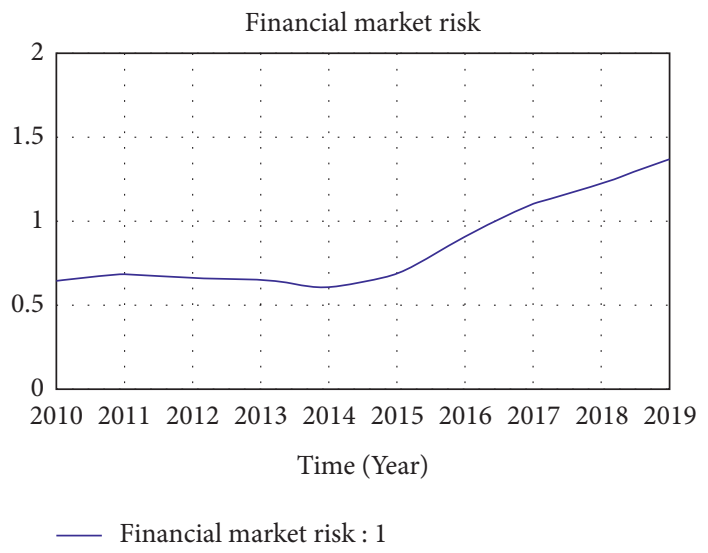

FIgURE 9: Financial market risk level from 2010 to 2019. 
Risks of non-financial enterprises and residents

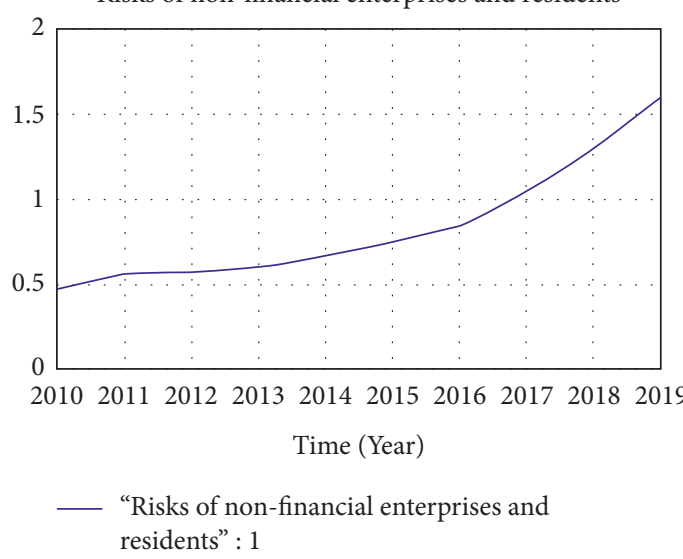

Figure 10: Nonfinancial enterprise and resident risk level from 2010 to 2019.

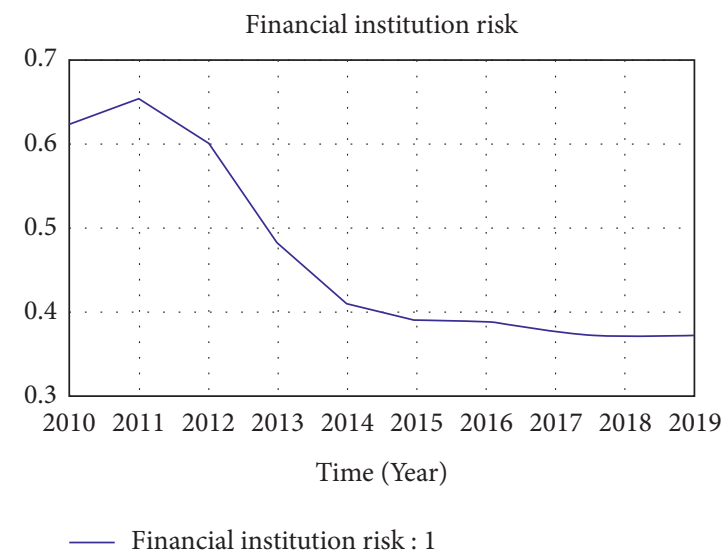

FIGURE 11: Financial institution risk level from 2010 to 2019.

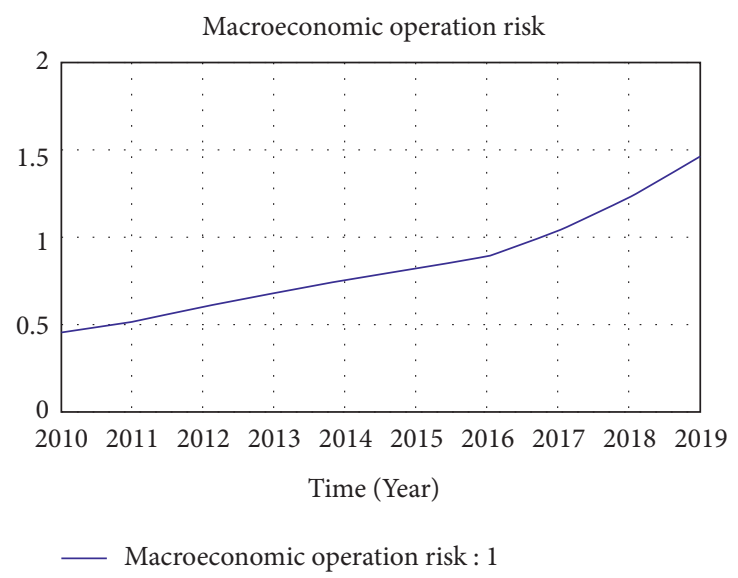

FIGURE 12: Macroeconomic operation risk level from 2010 to 2019. 


\section{Conclusions and Suggestions}

5.1. Conclusion. This paper establishes China's systematic financial risk evaluation model, based on the system dynamics model, and selects four dimensions: financial market, financial institutions, nonfinancial enterprises and residents, and overall economy. As the foundation for the development of China's comprehensive financial risk index model AHP and CRITIC are chosen on this basis to determine the index weights of submarkets and the weights of each submarket, in order to synthesize and comprehensively reflect systemic financial risk and each market's risk index, which is used to describe its state. The following is the final conclusion:

(1) The level of systemic financial risk is always greater than 0 , indicating that China's financial system as a whole is in a moderate financial risk state, as determined by the identification and analysis of China's systematic financial risk index.

(2) The systematic financial risk index from 2010 to 2019 is calculated using the CRITIC and AHP weighting methods. The findings show that financial institutions, financial markets, nonfinancial enterprises and residents, and macroeconomic operations, all play a role in China's financial risk index fluctuation. There are some systematic correlations, but there are also some differences between submarkets.

(3) There are significant differences in risk indices of each submarket in terms of fluctuation characteristics. The risk of macroeconomic operation increased to some extent between 2010 and 2019. In general, the financial risk fluctuation of Chinese financial institutions is not significant.

5.2. Policy Advice. Continue to encourage high-quality economic growth. Economic development of high quality is the only way to keep systemic financial risks at bay. We can only optimize the allocation of financial resources and resolve financial risks if we continue to promote high-quality economic growth.

Intensify the financial industry's "penetrating" supervision. "Penetrating" supervision is based on the principle that substance is more important than form, and it entails delving deeply into the true identity of financial market subjects behind financial activities, as well as identifying the transaction essence hidden beneath the formal cloak of complex financial products, in order to conduct targeted and deep supervision and adjustment of financial activities using effective supervision tools. "Penetrating" supervision can elucidate the logic of financial behavior, investigate the source of financial risks, and aid in the systematic prevention of financial harm.

Focus on nonfinancial enterprise risks, as well as preventing and controlling risks in resident departments. It is critical to limit the deviation from reality; reducing leverage is essential, and improving enterprise competitiveness is critical.

\section{Data Availability}

The data used to support the findings of this study are included within the article.

\section{Conflicts of Interest}

The authors declare that there are no conflicts of interest.

\section{Acknowledgments}

This work was supported by Key Project of Jilin Provincial Department of Education in 2020 "Study on Improving the Financing Efficiency of Small and Medium-Sized Enterprises in Jilin Province" (JJKH20201298SK) and the Social Science Foundation of Jilin Province in 2020 "Research on the Fiscal and Financial Policies to Support the Survival and Development of Small, Medium and Micro-sized Enterprises in Jilin Province under the Normal Epidemic Condition" (2020C027).

\section{References}

[1] N. Deren, "Structural deleveraging for preventing and resolving systematic financial risk[J]," Research on Contemporary China's Economic Transformation (English Version), vol. 2, no. 1, p. 9, 2019.

[2] T. P. Le and C. D. Pham, "The systematic risk estimation models: a different perspective[J]," Heliyon, vol. 6, no. 2, p. e03371, 2020.

[3] G. Iannotta, G. Pennacchi, and J. A. C. Santos, "Ratings-based regulation and systematic risk incentives," The review of $f_{i-}$ nancial studies, vol. 32, no. 4, pp. 1374-1415, 2019.

[4] Q. Kang, "Financial risk assessment model based on big data [J]," International Journal of Modeling Simulation \& Scientific Computing, vol. 10, no. 04, pp. 106-113, 2019.

[5] M. Mallikarjuna and R. P. Rao, "Evaluation of forecasting methods from selected stock market returns[J]," Innovation in Finance, vol. 5, no. 1, p. 16, 2019.

[6] K. Johnston, J. Hatem, T. Carnes, and A. Kosedag, "An empirical evaluation of dynamic vs static withdrawal strategies," Managerial Finance, vol. 45, no. 12, pp. 1509-1525, 2019.

[7] J. Sun, M. Zhou, W. Ai, and H. Li, "Dynamic prediction of relative financial distress based on imbalanced data stream: from the view of one industry," Risk Management, vol. 21, no. 4, pp. 215-242, 2019.

[8] S. Stoft, "How financial transmission rights curb market power[J]," Office of Scientific \& Technical Information Technical Reports, vol. 13, no. 1, pp. 9-20, 2019.

[9] X. Yang, S. Mao, and H. Gao, "Novel Financial Capital Flow Forecast Framework Using Time Series Theory and Deep Learning: a Case Study Analysis of Yu'e Bao Transaction Data [J]," IEEE Access, no. 99, p. 1, 2019.

[10] Yang Jingling, Tang Guoqiang, and Yang Duancui, "Risk measurement and performance evaluation of equity funds based on ARMA-GARCH family model[J]," Journal of Statistics (English), vol. 10, no. 2, p. 16, 2020.

[11] Na Guo, Qi Fan, and J. Li, “Analysis of China's systemic financial risk measurement and monetary policy impact mechanism[J]," Financial Forum, vol. 25, no. 4, p. 12, 2020.

[12] Z. Huang, Y. Liu, C. Zhan, C. Lin, W. Cai, and Y. Chen, "A novel group recommendation model with two-stage deep 
learning," IEEE Transactions on Systems, Man, and Cybernetics: Systems, Early Access, 2021.

[13] Y. Zhang, K. Xia, and Y. Jiang, "Multi-modality fusion \& inductive knowledge transfer underlying non-sparse multikernel learning and distribution adaption[J]," IEEE/ACM Transactions on Computational Biology and Bioinformatics, 2022.

[14] X.-B. Jin, W.-Z. Zheng, J.-L. Kong et al., "Deep-Learning temporal predictor via bidirectional self-attentive encoderdecoder framework for IOT-based environmental sensing in intelligent greenhouse," Agriculture, vol. 11, no. 8, p. 802, 2021.

[15] Research Group of Finance and Development Research Center, National Institute of Finance, and Tsinghua University, "Monitoring of China's systemic financial pressure [J]," International Financial Research, no. 12, p. 10, 2019.

[16] X. Yi and Q. Zheng, "Research on China's high-quality financial opening during the "14th Five-Year Plan" period [J]," Economic Research Reference, no. 10, p. 11, 2020.

[17] J. Zhou and Y. Li, "Review and enlightenment of research on systematic financial risk assessment methods[J]," Beijing Financial Review, no. 4, p. 8, 2019.

[18] X. Chen, H. Zhou, and T. Jin, "Comparison and applicability analysis of systemic financial risk indicators at the micro level-_based on the research of China's financial system[J]," Financial Research, vol. 000, no. 005, pp. 17-36, 2019.

[19] M. Wang, "How to identify the harm of systemic financial risks before they break out[J]," Enterprise Reform and Management, no. 15, p. 2, 2019.

[20] Y. He, "Systematic financial risk transmission mechanism, evaluation and management research from the perspective of RMB internationalization[J]," Journal of Honghe University, vol. 18 , no. 5 , p. 3, 2020.

[21] P. Wang, "Research on China's financial systematic risk assessment based on general cluster Analysis[J]," Financial Management Research, no. 2, p. 23, 2018.

[22] H. Lv, "Local government debt risk prevention and control system[J]," Chinese Agricultural Accounting, no. 3, p. 3, 2019.

[23] M. Chen, T. Zhao, and C. Liu, "Research on the dynamic evolution of system importance and resonance effect of crosssectoral financial institutions_- - based on the empirical study of China's A-share market[J]," China Management Science, no. 4, p. 12, 2020.

[24] X. Yang, B. Guo, and Mi Zhilong, "Identification algorithm for users with high default risk in Internet financial platforms [J]," Application Research of Computers, vol. 3, p. 6, 2019.

[25] S. Prinja, A. S. Chauhan, A. Karan, G. Kaur, and R. Kumar, "Impact of publicly financed health insurance schemes on healthcare utilization and financial risk protection in India: a systematic review," Plos One, vol. 12, no. 2, p. e0170996, 2017.

[26] N. Restrepo, J. M. Uribe, and D. Manotas, "Financial risk network architecture of energy firms," Applied Energy, vol. 215, pp. 630-642, 2018.

[27] K. Barnes, A. Mukherji, P. Mullen, and N. Sood, "Financial risk protection from social health insurance," Journal of Health Economics, vol. 55, no. sep, pp. 14-29, 2017. 